\title{
UNTERWASSER-BEOBACHTUNG VON CRUSTACEA DECAPODA REPTANTIA UND STOMATOPODA MIT HILFE EINES FOTOSCHLITTENS
}

Mit 1 Tabelle, 1 Textabblidung und 2 Tafeln

Von

Michael TÜRKAY

(Naturmuseum und Forschungs-Institut Senckenberg, Senckenberganlage 25, D 6000 Frankfurt an Main 1, Bundesrepublik Deutschland)

und

Hjalmar THIEL

(Institut für Hydrobiologie und Fischereiwissenschaft, Universität Hamburg Palmaille 55, D 2000 Hamburg 50, Bundesrepublik Deutschland)

ソリ式深海カメラによる十脚甲殼類は行類・ロ脚類の観察

表 1 , 插図 1 , 図版 2

M.トウルカイ

（ゼンケンペルグ博物館）

H. ティエール

(ハンブルグ大学)

\begin{abstract}
The pictures taken by the photosled in 13 lowerings in the upwelling area off NW-Africa and off Morocco show 13 species of Decapoda Reptantia and Stomatopoda. Only specimens which could be identified to generic level at least are dealt with and all others that can only be ranged in higher taxa (above generic level) are ecluded from consideration. 2. The perceptibility-limit of specimens is about $2-3 \mathrm{~cm}$ carapace breadth. 3. Most of the photographed species could also be obtained by trawls. 4. The photosled is shortly described with special regard to improvements. It is a useful tool for biological mapping of the sea floor.
\end{abstract}

I. Einleitung.

Die 36. Forschungsfahrt von F.S. "Meteor" galt während des 2. Abschnittes im Februar-März 1975 der weiteren Erforschung des Benthos im N. W.-afrikanischen 
Auftriebsgebiet. Neben Bodengreifern, Dredgen und Trawls wurde ein Fotoschlitten eingesetzt, um Informationen über große Epifauna und vagile Tiere zu erhalten. Diese werden mit den Sammelgeräten nicht quantitativ erfaßt, mit Hilfe der Fotografie lassen sich jedoch zahlreiche Aussagen machen.

Während der Expedition konnten 13 Einsätze mit dem Fotoschlitten gefahren werden, die sich auf drei Schnitte verteilen:

Schnitt 1 etwa $25^{\circ} 32^{\prime} \mathrm{N}$ nördliches Auftriebsgebiet, 5 Einsätze

Schnitt 2 etwa $21^{\circ} 20^{\prime} \mathrm{N}$ zentrales Auftriebsgebiet, 6 Einsätze

Schnitt 3 etwa $33^{\circ} 30^{\prime} \mathrm{N}$ kein oder sehr wenig Auftrieb., 2 Einsätze

Ein Bericht über die Expedition mit ausführlichen Stationsangaben ist in Vorbereitung (Hempel \& Thiel).

Die Auswertung der etwa 20.000 Aufnahmen hat gezeigt, daB auch zahlreiche Crustacea Decapoda in einem Umfang aufgenommen worden sind, wie das bei früheren Einsätzen des Fotoschlittens in verschiedenen Gebieten des Nordostatlantik nicht der Fall war. Die Erfahrung bei der Durchsicht der Filme hat gezeigt, daB die Informationen über die Epifauna, vagile Metazoen, Lebensspuren und Sedimentstrukturen so vielfältig sind, daß eine einmalige Betrachtung für eine entsprechende Auswertung nicht ausreicht. Wir legen mit dieser Arbeit die Ergebnisse über die Decapoda Reptantia und die Stomatopoda vor. Berichte über Fische, Echinodermen und Cnidarier werden folgen.

Wir danken den Herren Ing. J. BeHNkE (Deutsches Hydrographisches Institut, Hamburg) und Stud. rer. nat. R. Thomas (Universität Hamburg), die während der Expedition für die Einsätze des Fotoschlittens verantwortlich waren. Unser Dank gilt auch Herrn Dr. K. SAKAI (Carcinological Society of Japan) für die Übersetzung des Manuskripts ins Japanische sowie Kapitän und Besatzung von F. S. "Meteor".

\section{Der Fotoschlitten. (Taf. I)}

Der Fotoschlitten ist bereits früher (THIEL 1970, 1972) in seiner ersten Ausbauform beschrieben worden. Er hat Ähnlichkeiten mit der französischen "Troika" (Giermann, 1966). In dieser Arbeit sollen nur die wichtigsten Bauteile und die späteren Veränderungen sowie einige Einsatzerfahrungen beschrieben werden.

Der Schlitten ist eine schwere Eisenkonstruktion, deren Länge 4,4 m beträgt, die Breite ist $2,05 \mathrm{~m}$, die Höhe einschließlich des Úberrollbügels mißt $1.9 \mathrm{~m}$ Die Größe des Schlittens ergab sich bei der Konstruktion durch die Maßgabe, Hindernisse von etwa $60 \mathrm{~cm}$ Höhe noch überfahren zu können. Dieser Forderung hat der Schlitten bei Einsätzen auf unterseeischen Bergen beim Überqueren von Geröllfeldern entsprochen. Bei anderen Fahrten und auch während der Expedition "Meteor" 36 wurde er in Kalkriffe im Bereich der Schelfkante gefahren. Leichte Beschädigungen und Kalks- 
puren auch am Überrollbügel zeigten seine stabile Konstruktion, da nach dem Einstoppen des Schiffes und kurzzeitigem Anhieven des Gerätes die Einsätze ohne Funktionsausfall fortgesetzt werden konnten.

Das Blitzgerät und die Akkueinheiten sind nicht verändert worden. Verbesserungen konnten hingegen in der drucksicheren Kugel angebracht werden, die die Kamera trägt. Um Einsätze in der Tiefsee möglichst effektiv zu gestalten, wurde die kommerziell erhältliche Robot-Motorkamera mit dem $60 \mathrm{~m}$ Magazin gewählt. Diese konnten nur in einem kugelförmigen Gehäuse untergebracht werden.

Durch folgende Änderungen wurde das Kamerasystem verbessert:

-Eine Einspiegelung auf den entfernten Aufnahmebereich des Bildes erlaubt für jedes Bild die Dokumentation von Bildnummer, Uhrzeit und Stationsdaten. Beim Ausfall des Zählwerkes kann die Uhrzeit zur Zählung verwendet werden.

-Die fotographische Einheit ist als Block aus dem Gehäuse herausnehmbar, so daB der Filmwechsel im Laboratorium erfolgen kann, während das schwere Gehäuse im Schlitten montiert bleibt.

Beim Einsatz müssen Wassertiefe und gesteckte Trossenlänge aufeinander abgestimmt sein. Wird zu wenig Trosse gesteckt, erreicht der Schlitten den Grund nicht, wird zu viel Trosse ausgegeben, so kann diese durchhängen und das Sediment vor dem Fotoschlitten aufwühlen oder auch nur bewegliche Arten verscheuchen. Die erforderliche Trossenlänge wurde erfolgreich mit Hilfe einiger Diagramme von BLENDERMANN (1969) bestimmt. Sie bertug im allgemeinen das 2,5 fache der Wassertiefe. Schwierigkeiten ergaben sich nur dann, wenn der Fotoschlitten den Kontinentalhang hinaufgeschleppt wurde. Da sich die Wassertiefe während eines solchen Einsatzes dauernd verringert, muß die Trosse in kurzen Zeitabständen eingeholt werden. Die Geschwindigkeit des Fotoschlittens wird dadurch verändert und die räumlichen $\mathrm{Ab}$ stände $z$ wischen den Bildern werden ungleichmäBig. Die Korrelation $z$ wischen Bild und Wassertiefe wird dadurch eingeschränkt.

Erfolgreiche Einsätze sind bisher zwischen 30 und $3000 \mathrm{~m}$ Wassertiefe gefahren worden. Bei geringen Tiefen hat es sich bewährt, zwischen dem Hahnepot und der eigentlichen Schlepptrosse $100 \mathrm{~m}$ elastischer Kunststofftrosse einzusetzen. Bodenunebenheiten werden durch die Elastizität leichter und gleichmäßiger, mit weniger Schlammaufwirbelung überfahren. Bei einer Schleppgeschwindigkeit von $2 \mathrm{kn}$ und der am häufigsten verwendeten Bildfolgezeit von 2,5 sec ergibt sich eine fast lückenlose Kartierung des Meeresbodens und der fotografierbaren Organismen über eine Strecke von rund 2 Seemeilen. 
III. Die auf den Aufnahmen erkennbaren Arten.

1. ?Squilla mantis (LinnaeUs, 1758).

Station $94\left(25^{\circ} 11,7^{\prime} \mathrm{N} 15^{\circ} 47,8^{\prime} \mathrm{W}\right), 85 \mathrm{~m}$ Tiefe, Fotoschlitten 26, Bild Nr. 277.

Die auf dieser Station fotografierten Exemplare sind nicht mit letzter Sicherheit $\mathrm{zu}$ bestimmen, es handelt sich jedoch eindeutig um Stomatopoden, die in Körpergröße und Färbung sehr an Squilla mantis erinnern. Auch die Lokalität fällt in das Verbreitungsgebiet der Art. Nach MANNING (1970: 273 und 1973:21) ist sie aus dem Mittelmeer und im Atlantik von Mauretanien bis Angola bekannt. Die scheinbare Lücke zwischen diesen beiden Verbreitungsgebieten beruht allerdings offensichtlich nur auf $z u$ geringer Durchforschung der marokkanischen Atlantikküste. Da die Art auch in diesem Gebiet sogar kommerziell genutzt wird (Fischmarkt von Agadir.-dort erworbene Belegstücke befinden sich unter SMF 7158 in der Sammlung des Forschungsinstituts Senckenberg und wurden nach Auskunft von Fischern vor Agadir selbst erbeutet), ist anzunehmen, daß sie auch an der marokkanischen Atlantikküste häufig ist. Sie hat somit sehr wahrscheinlich ein geschlossenes Verbreitungsgebiet, das sich vom Mittelmeer bis Angola erstreckt.

2. Palinurus mauritanicus Gruvel, 1911. (Taf. II Fig. 1)

Station $105\left(21^{\circ} 15,3^{\prime} \mathrm{N} 17^{\circ} 29,8^{\prime} \mathrm{W}\right), 206-217 \mathrm{~m}$ Tiefe, Fotoschlitten 32, Bild Nr. ?639, 650, $651,657,795,819,855,924$, ?1178.

Diese Art ist auf der angeführten Station recht oft fotografiert worden und ist durch das charakteristische Färbungsmuster eindeutig zuzuordnen. Sie wurde auf der selben Station auch durch ein Kutter-Trawl erbeutet und scheint somit hier nicht selten zu sein. Sie wird zu kommerziellen Zwecken weiter südlich, vor der Banc d'Arguin, gefangen, wo die Populationsdichten besonders hoch sind. In wie weit die relativ große Zahl der fotografierten Tiere ein Indiz für ausbeutbare Populationsdichten ist, müßte durch eingehende fischereibiologische Untersuchungen geklärt werden.

Alle fotografierten Exemplare sitzen hochbeinig und mit nach hinten gelegten Antennen auf dem Sediment. Postel (1966: 432) weist bereits darauf hin, dab die Art keine besondere Biotopbindung besitzt, sich aber besonders gern in den am Kontinentalabhang befindlichen Korallen der Gattungen Dendrophyllia und Lophoelia aufhält.

3. Scyllarus sp.

Station $111\left(21^{\circ} 20,3^{\prime} \mathrm{N} 17^{\circ} 46,9^{\prime} \mathrm{W}\right), 65^{-114} \mathrm{~m}$ Tiefe, Fotoschlitten 35, Filmrolle 1 : Bild Nr. 177 .

Das fotografierte Exemplar gehört zwar eindeutig zur Gattung Scyllarus, eine 
Artbestimmung ist jedoch völlig unmöglich. Auf einer benachbarten Station wurden Vertreter dieser Gattung in sehr hoher Individuenzahl erbeutet. Die Art ist (vermutlich) $\mathrm{zu}$ klein, um regelmäßig und entsprechend ihrer Häufigkeit aufgenommen $\mathrm{zu}$ werden.

4. Dardanus arrosor arrosor (HERBST, 1796). (Taf. II Fig. 2)

Station $95\left(25^{\circ} 11,7^{\prime} \mathrm{N} 15^{\circ} 47,8^{\prime} \mathrm{W}\right), 85 \mathrm{~m}$ Tiefe, Fotoschlitten 26, Bild Nr. 31, 116, 126, ?430, ?716, 981, 1044, 1064 .

Station $96\left(25^{\circ} 24,2^{\prime} \mathrm{N} 15^{\circ} 57^{\prime} \mathrm{W}\right), 184-171 \mathrm{~m}$ Tiefe, Fotoschlitten 27, Bild Nr. 88, ?535, 704.

Station $105\left(21^{\circ} 15,3^{\prime} \mathrm{N} 17^{\circ} 29,8^{\prime} \mathrm{W}\right), 206-217 \mathrm{~m}$ Tiefe, Fotoschlitten 32, Bild Nr. 16, 19, 514, 516,644 , ?825.

Station $111\left(21^{\circ} 20,3^{\prime} \mathrm{N} 17^{\circ} 46,9^{\prime} \mathrm{W}\right), 65-114 \mathrm{~m}$ Tiefe, Fotoschlitten 35 , Filmrolle 1 : Bild Nr. 66, 79, Filmrolle 3 : Bild Nr. ?158.

Die Art ist im Gebiet sehr häufig und wurde auch entsprechend regelmäBig in allen Schleppgeräten, die an oder in der Nähe der angeführten Stationen eingesetzt wurden, gefangen. In die hier angegebene Liste der Aufnahmen sind nur solche Exemplare aufgenommen, die eindeutig $\mathrm{zu}$ identifizieren waren. Auf einer ganzen Reihe weiterer Aufnahmen sind Einsiedlerkrebse zu sehen, deren größter Teil sehr wahrscheinlich zu dieser Art gehört, aber nicht zweifelsfrei identifiziert werden kann.

5. Pagurus prideauxi LEACH, 1815. (Taf. II Fig. 3)

Station $111\left(21^{\circ} 20,3^{\prime} \mathrm{N} 17^{\circ} 46,9^{\prime} \mathrm{W}\right), 65-114 \mathrm{~m}$ Tiefe, Fotoschlitten 35, Filmrolle 1 : Bild $\mathrm{Nr}$. 149.

Die Art wurde durch auf benachbarten Stationen eingesetzte Schleppgeräte gefangen. Bei der Determination des fotografierten Tieres waren die Form und Haltung der großen Schere und der Laufbeine entscheidend. Auch die Körpergröße bestätigt die Zuordnung.

6. Munida speciosa von Martens, 1878. (Taf. II Fig. 4-6)

Station $104\left(21^{\circ} 23,5^{\prime} \mathrm{N} 17^{\circ} 32,4^{\prime} \mathrm{W}\right), 407-399 \mathrm{~m}$ Tiefe, Fotoschlitten 31, Bild Nr. 48, 56, 78, 90, 147, 176, 401, 564, 650, 764, 838, 920, 1327, 1343, 1378, 1505, 1547, 1548, 1562.

Station $105\left(21^{\circ} 15,3^{\prime} \mathrm{N} 17^{\circ} 29,8^{\prime} \mathrm{W}\right), 206-217 \mathrm{~m}$ Tiefe, Fotoschlitten 32 . Bildnummern s. Abb. 1.

Station $111\left(21^{\circ} 20,3^{\prime} \mathrm{N} 17^{\circ} 28,5^{\prime} \mathrm{W}\right), 114-65 \mathrm{~m}$ Tiefe, Fotoschlitten 35 , Filmrolle 1:

Bild Nr. 93; Filmrolle 4 : Bild um $23 \mathrm{~h} 37^{\prime} 18^{\prime \prime}$.

Diese Art ist auf Station 105 besonders häufig beobachtet worden. Sie ist auf Grund ihrer hochcharakteristischen Färbung nicht $\mathrm{zu}$ übersehen und $\mathrm{zu}$ verwechseln. Als eindeutiges Erkennungsmerkmal sind besonders die weißen Scherenspitzen geeignet, die sich deutlich vom roten Körper absetzen. Bereits STUDER (1883:28) hat die auffällige Färbung der Art zutreffend und genau beschrieben. 
Die Aufnahmen des Fotoschlittens lassen Aussagen über die Abundanz der Art in verschiedenen Tiefen zu. Besonders dicht ist die Besiedlung offenbar in ca. $200 \mathrm{~m}$ Tiefe. Mit zunehmender und abnehmender Tiefe verringert sich offensichtlich die Populationsdichte. Besonders deutlich wird diese Abnahme im flacheren Wasser (Station 111). Zieht man die Fänge der Schleppgeräte hinzu, so bestätigt sich das durch den Fotoschlitten ermittelte Phänomen. Die bisher publizierten Meldungen der Art lassen erkennen, daß dieses Maximum bei ca. $200 \mathrm{~m}$ Wassertiefe nicht auf das untersuchte Gebiet beschränkt ist.

Die Tiere sitzen auf dem Sediment und sind zum Fotoschlitten hin orientiert, wenn dieser in ihrer Nähe ist. Offenbar wird ab einer gewissen Mindestentfernung die dem Gerät vorangehende Druckwelle wahrgenommen. In einigen Fällen ist dann auch die Flucht der Tiere zu beobachten. Hierbei sind die Scheren gerade nach vorn gestreckt und die Beine dicht an den Körper gelegt. Das Abschwimmen erfolgt nach Macrurenart mit Hilfe von Pleonschlägen senkrecht nach oben. Dieses Verhalten konnte auch an lebend an Deck gebrachten Exemplaren beobachtet werden und könnte ein Grund für die relativ geringe Zahl der in Schleppgeräten gefangenen Exemplare sein.

Auf den Unterwasserfotos waren an keiner Stelle Mulden oder Sedimentwälle um die Tiere herum wahrzunehmen, jedoch war immer, auch auf den Stationen mit hoher Populationsdichte, ein gewisser Mindestabstand zwischen den Individuen zu beobachten. Inwieweit dies als Hinweis für Territorialität zu werten ist, muß eingehenden Aquarienuntersuchungen vorbehalten bleiben. Wie sich aus Abb. 1 entnehmen läßt, sind die Tiere nicht gleichmäßig im Biotop verteilt, sondern bilden $z$. T. etwas dichter zusammensitzende Gruppen, zwischen denen ein größerer Abstand $z u$ sein scheint. Die Frage ob diese "Herdenbildung" eine konstante Erscheinung ist, hängt eng mit der Frage nach der Territoritorialität und damit der Wanderintensität der Tiere zusammen und kann somit nicht abschließend beantwortet werden.

\section{Calappa granulata (Linnaeus, 1767). (Taf. II Fig. 7-8).}

Station $96\left(25^{\circ} 24,2^{\prime} \mathrm{N} 15^{\circ} 57^{\prime} \mathrm{W}\right), 184-171 \mathrm{~m}$ Tiefe, Fotoschlitten 27, Bild Nr. 95, 97, 112, 279, 438, 496, 525, 565, 905, 1072.

Die Art wurde nicht nicht mit Schleppgeräten erbeutet, die Fotografien zeigen jedoch sehr deutlich das charakteristische, aus roten Flecken bestehende Färbungsmuster auf den Wülsten des Carapax. Die fotografierten Exemplare laufen hochbeinig und mit angelegten Scheren auf dem Sediment. Dieses Verhalten wurde bereits von ScHÄFER (1954:22) nach Aquarienbeobachtungen beschrieben. Die direkte Beobachtung belegt nunmehr, daß die Tiere das gleiche Verhalten auch am Meeresboden zeigen. Da das Erkennen eingegrabener Individuen auf den vorliegenden Bildern un- 

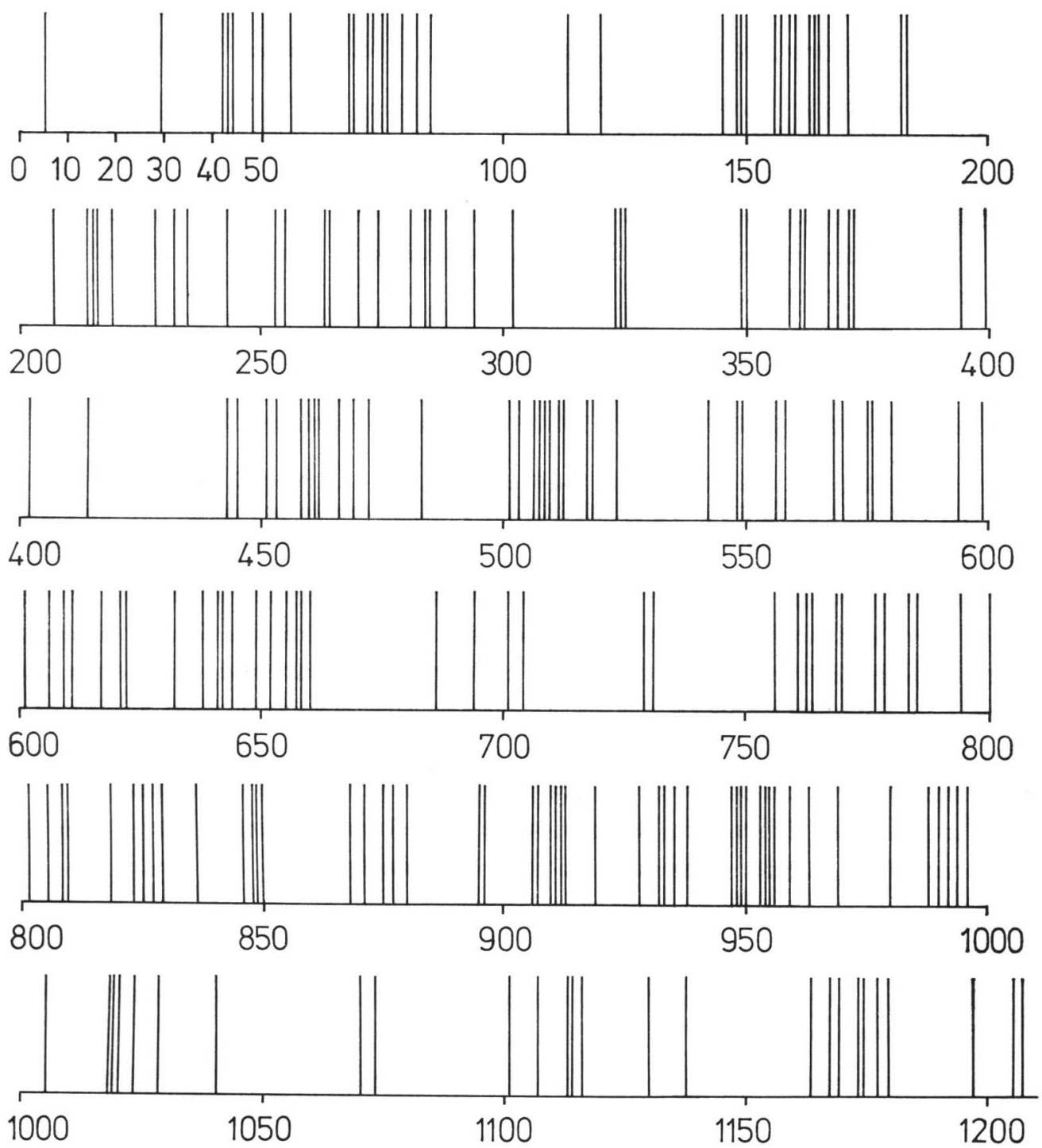

Abb. 1. Bildsequenz von Munida speciosa auf Station 105. Die Zahlen geben die Abbildungsnummern an, die senkrechten Striche symbolisieren die beobachteten Tiere unabhängig von der Anzahl je Bild.

möglich ist, können die Aufnahmen nichts über die Populationsdichte der Art aussagen. Es ist affallend, daß auf dieser Station eine relativ große Zahl von Tieren außerhalb des Sediments aktiv ist. Keinesfalls handelt es sich um aufgeschreckte Individuen. Inwieweit der Aufenthalt außerhalb des Sediments tagesperiodisch ist und mit der Uhrzeit der Beobachtung ( $23^{00}-00^{35}$ GMT) zusammenhängt, bleibt noch zu klären. 
8. Calappa ?pelii (Herklots, 1851).

Station $111\left(21^{\circ} 20,3^{\prime} \mathrm{N} 17^{\circ} 28,5^{\prime} \mathrm{W}\right), 114-65 \mathrm{~m}$ Tiefe, Fotoschlitten 35 , Filmrolle 1 : Bild Nr. 2.

Diese weiter südlich verbreitete Art ist nicht so eindeutig $\mathrm{zu}$ erkennen. Die Fotografie zeigt ganz klar das Fehlen des für die vorhergehende Art so charakteristischen roten Fleckenmusters. Damit kommt von Arten des Gebiets wohl nur pelii in Frage. Außerdem wurde pelii auf der benachbarten Station 106 mit Hilfe eines Agassiz-Trawls erbeutet.

9. Macropipus rugosus (Doflein, 1904). (Taf. II Fig. 9-10)

Station $105\left(21^{\circ} 15,3^{\prime} \mathrm{N} 17^{\circ} 29,8^{\prime} \mathrm{W}\right), 206-217 \mathrm{~m}$ Tiefe, Fotoschlitten 32, Bild Nr. 5, 229, ?536, 694, 803.

Station $111\left(21^{\circ} 20,3^{\prime} \mathrm{N} 17^{\circ} 28,5^{\prime} \mathrm{W}\right), 114-65 \mathrm{~m}$ Tiefe, Fotoschlitten 35 , Filmrolle 1 : Bild Nr. 111, Filmrolle 3 : Bild Nr. 64, 66, 201, 205, 250, 269, Filmrolle 4 : Bild 23h 40' 33"',23h $34^{\prime}$ 14", 23h 26' 10", Filmrolle 5 : Bild Nr. 115.

Diese Art wurde mit Hilfe von Schleppgeräten in großer Zahl auf den hier angeführten und weiteren Stationen erbeutet. Sie ist somit im Gebiet sehr häufig. Die fotografierten Exemplare sitzen meist auf dem Sediment und einige von ihnen schwimmen beim Herannahen des Fotoschlittens senkrecht nach oben ab, indem die Beine gerade vom Körper abgespreizt gehalten werden. Auf Station 111, Filmrolle 4: Aufnahme um $23 \mathrm{~h} 34^{\prime} 14^{\prime \prime}$ sind zwei Tiere zu sehen, die übereinander sitzen. Offenbar handelt es sich um ein Pärchen, wobei das $\hat{\delta}$ das 우, in der von Brachyuren bekannten Weise, bis zur Besamung mit sich herumträgt.

\section{Goneplax rhomboides (Linnaeus, 1758).}

Station $111\left(21^{\circ} 20,3^{\prime} \mathrm{N} 17^{\circ} 28,5^{\prime} \mathrm{W}\right), 114-65 \mathrm{~m}$ Tiefe, Fotoschlitten 35, Filmrolle 1 : Bild Nr. ?62, Filmrolle 4 : Bild 23h $38^{\prime} 43^{\prime \prime}$.

Diese Art wurde auf einer der benachbarten Stationen mit Hilfe von Schleppgeräten erbeutet. Das auf Filmrolle 4 um 23h $38^{\prime} 43^{\prime \prime}$ fotografierte Exemplar zeigt das typische Färbungsmuster der durch CAPART (1951) als angulata bezeichneten Form, die durch einen spitzen Epibranchialzahn gekennzeichnet ist. Beide Formen (mit und ohne Epibranchialzahn) wurden in den Fängen der Expedition festgestellt, wobei die Form angulata (mit Epibranchialzahn) nur im Gebiet von Cap Blanc und die Form rhomboides (ohne Epibranchialzahn) nur auf den nördlichen Stationen gefangen wurde. Im frischen Zustand unterscheiden sich beide Formen sehr deutlich durch die Färbung des Carapax. Während die Form ohne Epibranchialzahn gleichmäßig rosa gefärbt war, wies der Carapax der anderen Form zwei tiefrote Querbinden in der vorderen Carapaxhälfte auf, die auch bei dem einen fotografiereten Exemplar 
deutlich zu erkennen sind. Das Exemplar auf Filmrolle 1: Bild Nr. 22 ist in dieser Hinsicht zu undeutlich abgebildet.

11. Inachus $s p$. (Taf. II Fig. 11-12)

Station $111\left(21^{\circ} 20,3^{\prime} \mathrm{N} 17^{\circ} 28,5^{\prime} \mathrm{W}\right), 114-65 \mathrm{~m}$ Tiefe, Fotoschlitten 35, Filmrolle $3:$ Bild Nr. ?74, 83, ?203, ?206, 209, 231, Filmrolle 4 : Bild 23h 41' 52".

Auf einigen Bildern läBt sich deutlich erkennen, daB es sich bei den abgebildeten Tieren um Angehörige der Gattung Inachus handelt. Eine Zuordnung $z u$ einzelnen Arten ist jedoch nicht möglich. Auf benachbarten Stationen wurden eine ganze Anzahl von Inachus-Arten gefangen, so daB eine Eingrenzung in dieser Hinsicht auch nicht in Frage kommt.

12. ?Macropodia sp.

Station $111\left(21^{\circ} 20,3^{\prime} \mathrm{N} 17^{\circ} 28,5^{\prime} \mathrm{W}\right), 114-65 \mathrm{~m}$ Tiefe, Fotoschlitten 35, Filmrolle 3 : Bild Nr. 107.

Die Zuordnung dieser und mehrerer anderer Aufnahmen ist recht fraglich. Das angeführte Bild läßt einen Angehörigen der Inachinae mit sehr dünnen Beinen und einem ziemlich spitz-dreieckigen Carapax erkennen, so daß die Zuordnung zur Gattung Macropodia recht wahrscheinlich ist. Alle anderen Aufnahmen lassen noch weniger erkennen und somit auch keine Entscheidung zwischen den verschiedenen Gattungen des Gebiets zu. Sehr wahrscheinlich liegt die Größe der Tiere schon unterhalb der Aufösungsgrenze. Jedenfalls wurden Vertreter von Macropodia in großer Anzahl auf benachbarten Stationen gefangen.

13. ?Parthenope massena (Roux, 1830).

Station $111\left(21^{\circ} 20,3^{\prime} \mathrm{N} 17^{\circ} 28,5^{\prime} \mathrm{W}\right), 114-65 \mathrm{~m}$ Tiefe, Fotoschlitten 35, Filmrolle 1 : Bild Nr. 149 .

Auch dieses Exemplar liegt wegen seiner geringen Größe wohl bereits unter der Auflösungsgrenze, so daß es nicht eindeutig zuzuordnen ist. Die Körperform erinnert jedoch stark an Parthenope massena, die auch auf benachbarten Stationen gefangen werden konnte.

IV. Ergebnisse der Auswertung.

Auf den Aufnahmen des Fotoschlittens sind 13 Arten der hier ausgewerteten Tiergruppe erkennbar. Eine ganze Reihe anderer Aufnahmen mit Decapoden liegt zwar vor, jedoch können diese Tiere nur Großgruppen wie etwa Paguridea oder Brachyura zugeordnet werden. Sie sind bei der Aufnahme vom Fotoschlitten zu weit entfernt, $\mathrm{zu}$ klein oder hinter Sedimentaufwerfungen und in Löchern teilweise ver- 
borgen. In dem Abschnitt III dieser Arbeit wurden daher nur die zumindest auf dem Gattungsniveau eindeutig erkennbaren Tiere aufgenommen. Analysiert man die ungefähre Körpergröße der abgebildeten und eindeutig erkennbaren Tiere, so ist festzustellen, daß offensichtlich die Grenze der Erkennbarkeit bei einer Körpergröße von etwa $2-3 \mathrm{~cm}$ liegt. Dies wird besonders deutlich bei den in Abschnitt III angeführten Vertretern der Gattungen Inachus und Macropodia, die zwar einschlieBlich ihrer Beine die Auflösungsgrenze stark überschreiten und damit stets als Inachinae zu erkennen sind, deren kleiner Carapax jedoch die Entscheidung zwischen beiden Gattungen oft unmöglich macht. Aus diesen Tatsachen erklärt sich wohl auch, daß die Zahl der fotografierten Arten nur einen kleinen Bruchteil der ca. 90 mit Schleppgeräten erbeuteten Arten ausmacht. Die Mehrzahl der nicht fotografierten Arten ist bezeichnenderweise von geringer Körpergröße, andere führen eine versteckte Lebensweise oder treten in $z u$ geringer Populationsdichte auf.

Stellt man die Häufigkeit der Aufnahmen und die Information bezüglich der Feststellung der gleichen Arten mit Hilfe von Schleppgeräten in einer Tabelle zusammen, so ergibt sich folgende Übersicht:

Tabelle 1. Anzahl der fotografierten und zugeordneten Exemplare nach Arten und Stationen. Für die Arten sind die Schlüsselzahlen in Abschnitt III verwandt. Die Rubrik “Fang” gibt an, ob die Art auf der entsprechenden Station mit Hilfe von Schleppgeräten erbeutet werden konnte $(+=\mathrm{ja},-=$ nein).

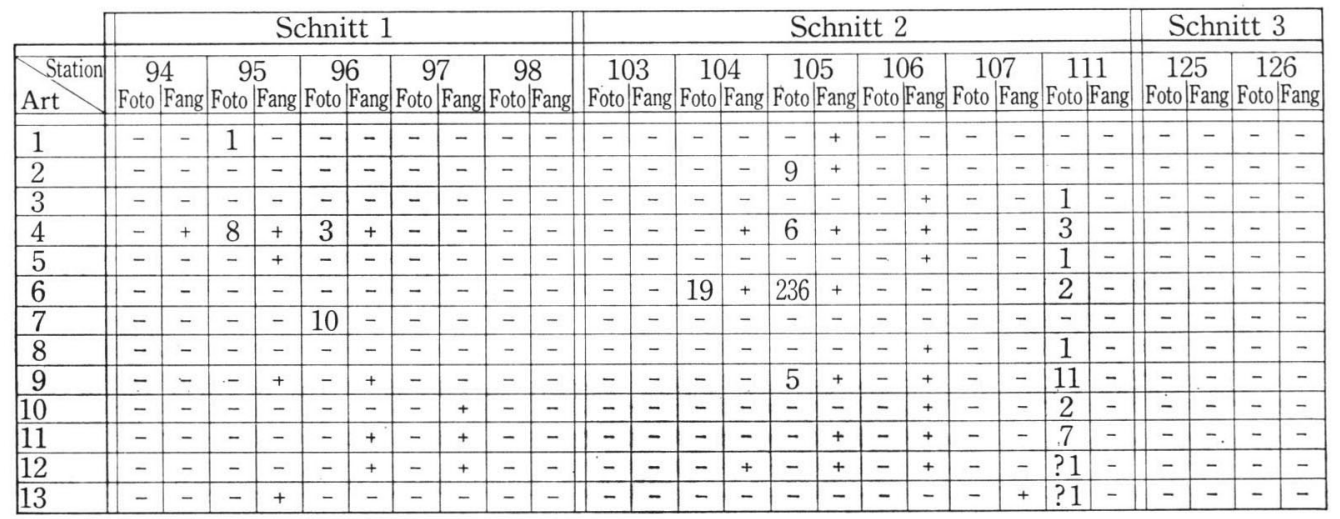

Aus der Zusammenstellung in Tabelle 1 geht hervor, daß der größte Teil der fotografierten Arten auf derselben oder auf benachbarten Stationen durch Schleppgeräte erbeutet werden konnte. Unsere Aufnahmen und Fänge zeigen, daB Fotografien nur gelingen, wenn eine genügend hohe Populationsdichte vorhanden ist. Munida speciosa wurde sogar viel häufiger fotografiert als gefangen, so daB erst durch den Fotoschlitten die Aussage gesichert werden kann, daß diese Art in der Tiefenzone um $200 \mathrm{~m}$ besonders häufig vorkommt. Diese Beobachtungen bestätigen, da $B$ der Foto- 
schlitten zur Kartierung großer Organismen und von Sedimentstrukturen des Meeresbodens besonders geeignet ist. Natürlich mussen Einchränkungen in Hinblick auf Körpergröße, Lebensweise und Populationsdichte gemacht werden. Hinweise auf die Endofauna lassen sich durch ihre Lebensspuren erhalten. Gerade in der Erfassung von Arten mit großer Populationsdiche liegt aber auch der Vorteil der Methode, da besonders diese häufigen Formen als Charakterarten einer Zonierung in Frage kommen (unveröffentlichte Beobachtung).

Insgesamt ergibt die Zusammenstellung in Tab. 1 eine große Zahl von fotografierten Tieren auf Schnitt 2, während Schnitt 1 in dieser Hinsichtärmer ist und auf Schnitt 3 überhaupt keine Krebse aufgenommen wurden. Geht man von gleichmäBigen Einsatzbedingungen aus, so bedeuten diese Ergebnisse, da $\mathrm{B}$ die Gesamtbesiedlungsdichte an Organismen auf Schnitt 2 viel höher liegt als auf Schnitt 1 und auf Schnitt 3. Diese Abnahme der Individuendichte von Süd nach Nord war aüch sehr deutlich in den Fängen der Schleppgeräte festzustellen. Offensichtlich ist also in der Region des Schnittes 2 (zentrales Auftriebsgebiet) das Nahrungsangebot größer als weiter im Norden.

V. Zus a m menfassung.

1. Auf den Aufnahmen des Fotoschlittens konnten 13 Arten Decapoda Reptantia und Stomatopoda erkannt und zumindest bis zum Gattungsniveau zugeordnet werden. Weitere, nicht eindeutig erkennbare Arten sind nicht in die Liste aufgenommen worden.

2. Die Grenze der Erkennbarkeit liegt bei einer Körpergröße von etwa $2-3 \mathrm{~cm}$.

3. Die fotografierten Arten konnten auch größtenteils mit Hilfe von Schleppgeräten erbeutet werden.

4. Der Fotoschlitten wird kurz beschrieben und die Verbesserungen werden kurz erwähnt. Das Gerät hat sich zur biologischen Kartierung des Meeresbodens weitgehend bewährt.

\section{Zitierte Literatur.}

Blendermann, W. (1969): Diagramme zur Bestimmung der Längen und Kräfte für eine Schlepptrosse bei ebener Belastung.-Inst. Schiffsbau Univ. Hamburg, Schrift 2163: 1-11, Diagramm 1-36.

CAPART, A. (1951): Crustacés Décapodes, Brachyures.-Exp. oceanogr. Belge, Eaux cotières afr. Atl. sud, Rés sci., 3(1) : 11-205, Abb. 1-80, T. 1-3.

Giermann, G. (1966) : Tauchkugel Soucoupe Plongeaute und Fotoschlitten Troika, zwei neue Werkzeuge für die geologische Unterwasserkartierung.-Dt. hydrogr. Z., 19: 170-177.

Manning, R. B. (1970): The R/V Pillsbury deep-sea biological Expedition to the Gulf of Guinea. 1964-65.-13-The Stomatopod Crustacea.-Stud. trop. Oceanogr., 4(2) : 256-275, Abb. 1-4.

- (1973) : Campagne de la Calypso dans le Golfe de Guinée et aux iles Principe, Sao Tomé et Annobon (1956), et Campagne aux Iles du Cap Vert (1959). 21. Stomatopod Crustacea.-Res. sci. Camp. "Calypso", $10: 1-22$, Abb. 1-6. 
Postel, E. (1966) : Langoustes de la zone intertropicale africaine.-Mém. Inst. fond. Afr. noire, 77 : 395-474, Tabelle 1-27, Abb. 1-15.

SchäFER, W. (1954): Form und Funktion der Brachyuren-Schere.-Abh. senckenb. naturf. Ges., 489 : 1-65, Abb. 1-128.

Studer, T. (1883) : Verzeichnis der Crustaceen welche während der Reise S.M.S. Gazelle an der Westküste von Afrika, Ascencion und dem Kap der guten Hoffnung gesammelt wurden. -Abh. königl. Akad. Wiss. Berlin, 1882 : 1-32, T. 1-2.

Thiel, HJ. (1970): Ein Fotoschlitten für die biologische und geologische Kartierung des Meeresbodens.-Mar. Biol., 7(3) : 223-229, Abb. 1-9.

(1972) : Survey-Apparates used by R. V. "Meteor", especially about the Photo-Sled.Benthos Ken-Ren-Shi (Periodical of the Benthos Research Group of Japan) Tokyo, 5/6 : 53-54, Abb. 1-3.

\section{Figure-explanations Taf. I}

Fig. 1. Fotoschlitten von vorn; Kamera und Blitz sind durch die Arbeitsöffnung zu sehen.

Fig. 2. Fotoschlitten von oben mit eingesetztem Kugelgehäuse für die Kamera, darunter der Blitz und hinten zwischen dem aufgewölbten Bodenblech und der Seitenplatte das Druckgehäuse mit der Batterie.

\section{Figure-explanations Taf. II}

Fig. 1. Palinurus mauritanicus, Station 105 Bild 650.

Fig. 2. Dardanus arrosor, Station 111 Filmrolle 1 : Bild 66.

Fig. 3. Pagurus prideauxi (links) und ?Parthenope massena (rechts), Station 111, Filmrolle 1: Bild 149.

Fig. 4. Munida speciosa, lebendes Exemplar von Station 104 an Deck von F. S. "Meteor" (Aufn. M. GRASSHOF).

Fig. 5. Munida speciosa, Station 105 Bild 465.

Fig. 6. Munida speciosa, Fluchtreaktion, Station 105, Bild 163.

Fig. 7. Calappa granulata, Station 96 Bild 438.

Fig. 8. Calappa granulata, Station 96 Bild 97.

Fig. 9. Macropipus rugosus, Pärchen vor der Kopulation, Station 111 Bild um 23h34'14".

Fig. 10. Macropipus rugosus, Fluchtreaktion, Station 111 Filmrolle 1: Bild 111.

Fig. 11. Inachus sp., Station 111 Filmrolle 3: Bild 209.

Fig. 12. Inachus sp. Station 111 Filmrolle 3 : Bild 231.

\section{I 緒 言}

探険船メティオア号による第36回海洋探険の5ちで，2 番目に行なわれた，1975 年 2 月〜 3 月に拈ける北西アフリカ上昇海流地域での広範なベントスの調査は極めて価值の高いものとな った。採泥器・ドレッヂ・トロールの他に, ソリ式深海カメラを併用して写真撮影をすること によって，多くの底生動物や浮遊動物に関する知識を得ることができた。

今回の調查では下記の 3 区でソリ式深海カメラを13回にわたり使用した。

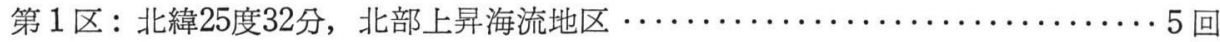

第 2 区：北緯 21 度 20 分, 中部上昇海流地区 $\cdots \cdots \cdots \cdots \cdots \cdots \cdots \cdots \cdots \cdots \cdots \cdots$ 


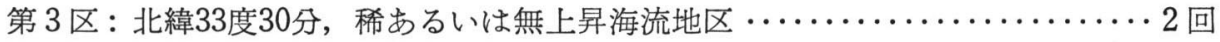

撮影した約 2 万枚の写真によると, 十脚甲殼類がある一定地域に多く認められ，大西洋北東 部の諸地域で以前に行なった同様な調査の結果とは著るしく異っていた。写真を検討した結 果, 底生動物・浮遊性後生動物・生物が生息する痕跡・堆積物構造の多様性などがみられ, 1 回の調査では充分な解析ができないことを知った。この報告では十脚甲殼類（は行類）と口脚 類に拈ける調査結果のみを述べることのみにとどめる。

II ソリ式深海カメラ (Taf. I)

このカメラの構造は，すでに報告されているように（THIEL，1970, 1972)，フランス製 “トロ イカ” (GIERMANN, 1966) 飞似ている。重要な構造上の特徵, 改良部, 使用にあたって体験し たことを二三述べる。

ソリは鉄製で非常に重く, 長さ $4.4 \mathrm{~m}$, 幅 $2.05 \mathrm{~m}$, 高さは保護枠を含めて $1.9 \mathrm{~m}$ である。こ の構造は高さが $60 \mathrm{~cm}$ 漂どの障害物に対しては影響されず，海底山に散在する堆積物上をけ ん引するのに適している。今回の探険でも,これまでと同様に, ソリ式深海カメラは石灰岩礁 地帯で使用されたが，破損はわずかで，その構造の安全性が実証された。また短時間で引き上 げても支障なく継続して使用することができた。

照明装置およびバッテリーには何ら改良が加兄られていないが，カメラを内臓する耐圧力力 プセルには改良がなされた。最も効果的に深海でカメラを操作するために， $60 \mathrm{~m}$ の長巻きフ ィルムを内蔵できる市販の自動遠隔操作カメラを用い, これを球形のカプセルに納めた。フィ ルムにはこまごとにフィルム番号・時間，地点が記録されるよ5にしてあり，番号読みとりに 故障が起さても，時間の記録がこれを補らことがでさるよ5になっている。また，重い矢倉を ソリにつけたまをでカメラを取り外し，フィルムを交換できるように改良された。

ソリを海底に沈める場合に, 水深とロープの長さを同じにする必要がある。即ち, ロープが 短かい時にはソリが海底に達せず, 長すぎる場合にはソリの前方の堆皘物を舞い上がらせ, 浮遊 動物を追い払 5結果になる。必要なロープの長さは水深を 2〜5 段階に分けた BLENDERMANN （1969）の図表が有効であった。

一つの問題は, このソリ式深海カメラが大陸棚の斜面上を深い所から 浅い所へ向って引きず られた時であった。水深が浅くなるために，早くロープをたぐらねばならず，その結果，力メ ラの進行速度が変わり, 撮影されたフィルムのこまは一定の距離を示さず, 水深の標示も不確 定になることであった。

今回の水深 $30 \sim 3000 \mathrm{~m}$ でのカメラの操作は, カメラに結んであるロープの分岐点と引き綱 の間に弾力に富んだ $100 \mathrm{~m}$ の化繊ロープを使用することによってこの標本に関する問題を解 決した。けん引速度は 2 ノット, 最高撮影間隔 2.5 秒の条件で, 約 2 マイルにわたる海底の状 態と撮影可能な動物のほど完全な図がでさ上った。

III 写真による種の同定

1) ?Squilla mantis (Linnaeus, 1758)

St. 94 で撮影された種で，完全な同定はできないが，まぎれもなくロ脚類で，その体長や色 彩から Squilla mantis と推定される。採集地点はこの種の分布地域内に含をれている。MAN- 
NING (1970：273, 1973：21) によれば, Squilla mantis は, 地中海と, アフリカ大西洋沿岸 のモーリタニアからアンゴラまでの地域に分布する。しかし，モーリタニアから地中海までの 地域, 特モロッコ大西洋沿岸は調査が不充分であったようで, 実際にはこの地域ではこの種が 漁獲対象の一つとなっており，豊富であることは否定できない（アガディール (Agadir) 魚市 場——ゼンケンベルグ博物館標本 No. 7158 和よびアガディール漁民からの情報)。従って, Squilla mantis は地中海からアンゴラにかけて分布していると訂正される。

2) Palinurus mauritanicus Gruvel, 1911. (Taf. II Fig. 1)

この種は St. 105 ではしばしば撮影され，その特徵のある鮮かな色彩や模様ではっきりと同 定される。また，この種はカッタートロールによっても採集されるので多く生息するものと考 えられる。南方の Banc d'Arquin 地域では生息密度が高く, 漁獲対象となっている。調査し た地区でぞの程度まで漁獲対象として期待できるかについては，今後明らかにされなければな らない。

写真によるとこの種は, 堆積物の上に胸脚で立ち, 触角を後方に向けている。PosTEL (1966: 432）がすでに 報告しているょうに，この種は何ら特殊な生活圈を持たず，大陸棚の斜面の Dendrophyllia と Lophoelia のサンゴ礁を特に好んで生息場所としている。

3) Scyllarus sp.

種の同定をでは不可能で, Scyllarus 属であることは明らかである。隣接する地点でも多数 採集されたが, 被写体としては小さ過ぎるため, 明らかでないが実際にはかなりの生息密度で あると考光られる。

4) Dardanus arrosor arrosor (HERBST, 1996) (Taf. II Fig. 2)

この種は St. 95, 96, 105, 111 で撮影され，非常に多くみられ，カメラと同時に用いた底引 き網には常に多数が入った。ここに示された写真番号のリストは確実に同定可能であったもの のみを取り上げている。他の，撮影された多くの写真にもこの種と思えるヤドカリが撮れてい るが同定はできない。

5) Pagurus prideauxi LEACH, 1815 (Taf. II Fig. 3)

St. 111 付近で，底引き網によって採集された。写真での種の同定は，針脚や胸脚の形々位 置でなされたが，体長も重要な要素である。

6) Munida speciosa (Von MARTEns, 1878) (Taf. II Fig. 4-6)

この種は St. 105 で特に多く観察された。極めて特徽ある色彩, 即ち赤い甲皮からはっきり と浮きだしてみ兄る鈿脚の白い先端は見過されたり，判別を間違えられたりすることはない。 すでに STUDER (1883: 28) は, この種の色彩の特徴を適確に，かつ詳細に記述している。

ソリ式深海カメラによる写真から判断すると, この種は水深に関して巾の広い生息域を持ち, 特に水深約 $200 \mathrm{~m}$ 付近が群集密度が高く，とれより水深が浅くなっても深くなっても個体数は 減少する。特に浅海 (St. 111) ではとの数は僅かであった。併用した底引き網による採集物か らもこのことが証明された。この事実は今回の調査地域に限られたことではない。

この種は堆積物上に生息し，ソリ式カメラが近ずく方向へ体を向忊るカカラの移動による 水圧の変化を, ある一定距離から感じ始めるといえる。カメラが接近すると, その場所から逃 げることも観察された。その行動では針脚を前方へ突きだし，他の脚を体につけ，エビ類と同様 に腹肢を動かし垂直上方へ泳ぎ去る。このことは底引き網による捕獲量が比較的に少ない理由 
の一つと考光てよかろ5。写真によると個体の周囲には堆皘物の壁やかこみは認められないが, 群集密度の高い場所では，個体間に常に一定の距離が保たれている。これがどの程度のなわ張 り性を示すかについては，詳細な調査が必要である。挿入図 1 から推定できるように，この種 は個体が一様に分布するのではなく，集団を作り，集団と集団の間にはより広い間隔があるら しい。この集団の形成が，この種の特異性であるかどらかについては，なわ張りや移動とも関 連しているため，今は最終的な結論は下せない。

7) Calappa granulata (Linnaeus, 1767) (Taf. II Fig. 7-8)

この種は St. 96 でみられら，底引き網にはかからなかったが，写真には隆起した甲皮と，そ の上にある赤色斑点の模様がはっきりとみられる。写真の個体は，鋁脚を堆積物の上に扔ろし， 高姿勢で歩行している。この行動については SCHÄFER (1954: 22) が，水槽内での観察によ って報告しているが，今回は，この種が海底でも同様な動きをすることがわかった。このカニ が堆積中に潜っていることも考えられるので，生息密度を推定することはできない。St. 96 で は比較的多くの動物が堆積物上で活動しているのが目立ったが，これは決して何かに驚いて動 物が跳ね上ったのではない。堆積物上での活動がある程度日周性を持つものか, 観察時間 (2300 一 $00^{85}$ 標準時）にどのように関係しているかは，更に明らかにされなければならない。

8) Calappa ?pelii (Herklots, 1851)

St. 111 から更に南にかけて分布しているこの種は明確な同定はできない。前種にみられた 甲皮の斑点模様はない。この地域に分布する種として C. pelii のみが考学られる。C. pelii は St. 106 付近でもアガジッットロール (Agassiz-Trawls) によって採集された。

9) Macropipus rugosus (Doflein, 1904) (Taf. II Fig. 9-10)

この種は底引き網で, St. 105, 111 抢よび他の地点でも多数が採集されたので，生息数は非 常に多いとい方る。写真に撮られた個体は大部分が堆積物上にみられるが，カメラが接近する と何個体かは脚を伸ばして 垂直に上方へ泳ぎ去る。St. 111 フィルム番号 4 , 撮影時間 23 時 34 分14秒では 2 個体が重り合っているのが観察された。これは明らかに雌雄一対である。

10) Goneplax rhomboides (LinNaEus, 1758)

この種は St. 111 付近で底引き網によって採集された。23時38分43秒に撮影されたフィルム 番号 4 にみられる標本には, CAPART (1951) が G. angulata の特徵として示した色彩や模様 と先鋭な鰓外棘がある。今回の調査の標本から，Goneoplax には 2 種めり，鰓外棘を有する G. angulata と鰓外棘がないG. rhomboides があることが確認された。前者は Cap Blanc 付近での久採集され，後者は北部の地点のみで採集された。この 2 種は生時，甲皮の色によっ て明らかに区別される。G. angulata は甲皮が一様にピンクであるが，G. rhomboides では， 写真にみられるよ5に, 甲皮前半に走る 2 本の深紅色の横帯がある。フィルム番号 4 , 写真番 号62の標本は，この特徽がはっきりしない。

11) Inachus sp. (Taf. II Fig. 11-12)

写真では種の同定までは不可能であるが，今回の調査地域で多くの Inachus 類が採集され た事実から，この種の分布が一定地域に限定されることはない。

12) ?Macropodia sp.

写真からでは種の同定は不可能である。非常に細い脚と 鋭角三角形の甲皮から Inachinae で, 多分 Macropodia 属であると考光られるが, 明確ではない。同定の困難さは個体の大きさ 
に関係している。この類は多数採集された。

13) ?Parthenope massena (Roux, 1830)

標本は体長が微小で同定できない。甲皮の形から，Parthenope massena とみられるカニが 採集された。

IV 検 討

ソリ式深海カメラによって撮影され，本論文で評価検討された写真から，13 種の動物が同定 されるが，その他の写真では単に異尾類・短尾類としか判別できない。この理由は, ソリ式深 海カメラ撮影で, 被写体の動物が遠すぎたり, 微小であったりしたこと, また, 堆積物の拡散 による撮影の阻害や被写体の逃げ去りなどがあげられる。したがって 2 回目の調査では，少な くとも属単位で同定可能なものだけがとりあげられた。写真で明確に同定できる動物の体長は $2 \sim 3 \mathrm{~cm}$ 以上である。

写真撮影された動物の種の数は，底引き網で採集された約 90 種の内の注んの一部にすぎない。 写真上に現われなかった多くの種は，著るしく小さいか，堆積物中に潜っていたか，または， 生息密度が非常に底いかのいずれかを意味している。写真撮影と同時に底引き網で採集された 個体の状況は第 1 表に示してある。撮影された種の大部分は底引き網によって採集されてい る。写真撮影は生息密度の高い場合に効果がある。Munida speciosa は底引き網によって採集 された数より写真撮影された数の方が多く, また, 水深 $200 \mathrm{~m}$ 付近に特に多く生息している事 実が初めて確認された。

上記のことから, ソリ式深海カメラが，比較的に大型の種の分布や海底の堆積物の様子を知 る上で非常に 適しているが，動物の大きさ，その生活様式や生息密度などによって制約され る。をた生痕も動物の生息状況を知る手がかりとなり得る。生息密度の高い種の把握がカメラ による調査の利点であるから，しばしば写真に現われる種をある地域の代表種と考えることが できる。

表 1 をみると, 表 1 区では非常に多くの動物の写真が撮影されたが, 第 2 区ではその数は減 少し，第 3 区では全くカニの写真は撮られていない。第 2 地区の動物生息密度が第 1 ・第 3 地 区よりも高いことを意味している。南から北へ行くにつれ，動物の生息する数が減少している 事実は，底引き網による採集物によっても実証された。従って第 2 地区（中部上昇海流地区） には北部よりも䬣が豊富であるといえる。

\section{$\mathrm{V}$ 結 論}

1) ソリ式深海カメラによる調査では，13種のは行類と口脚類が認められ，少なくとも属単 位で同定された。

2) ソリ式深海カメラによる同定可能な個体は体長 $2 \sim 3 \mathrm{~cm}$ 以上である。

3）写真撮影された種の大部分は底引き網によって採集された。

4）ソリ式深海カメラについては，その改良部分についても簡単に説明した。このカメラが 底生動物分布地図作成に非常に有効であることが証明された。 


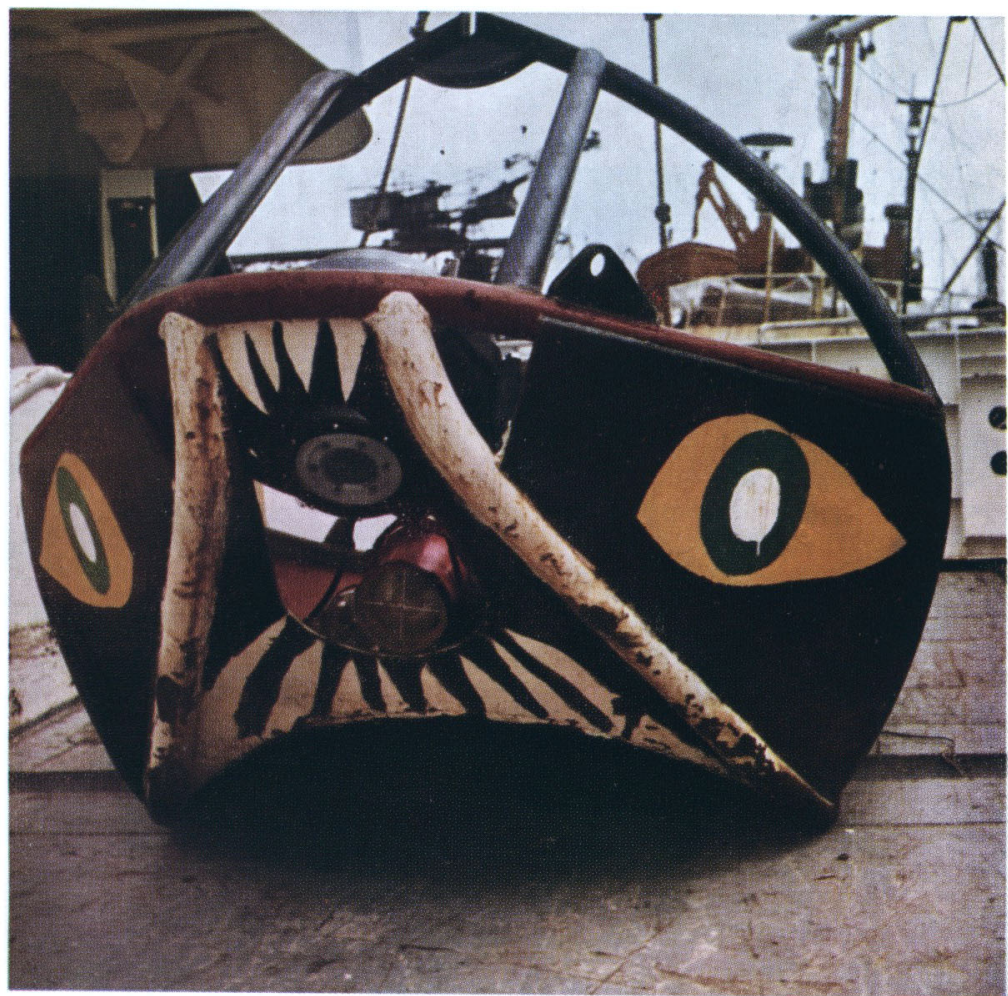

Fig. 1

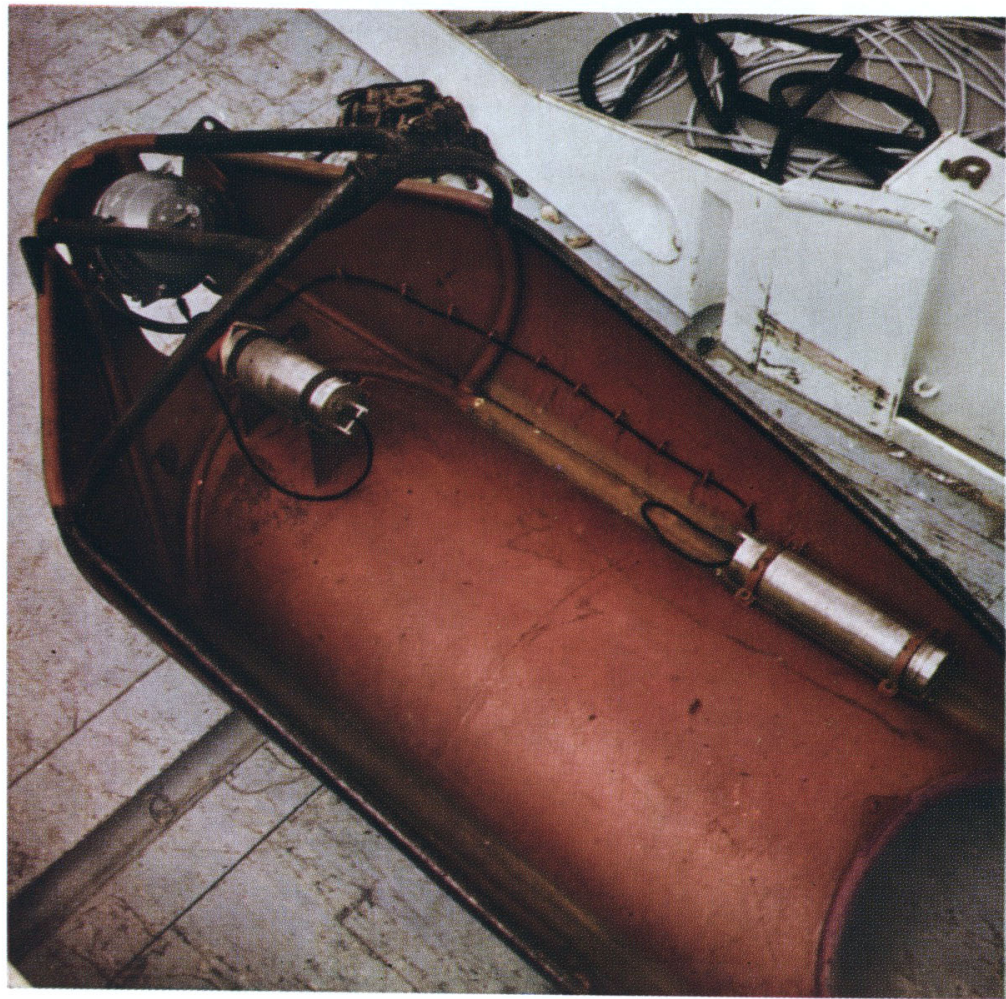

Fig. 2. 


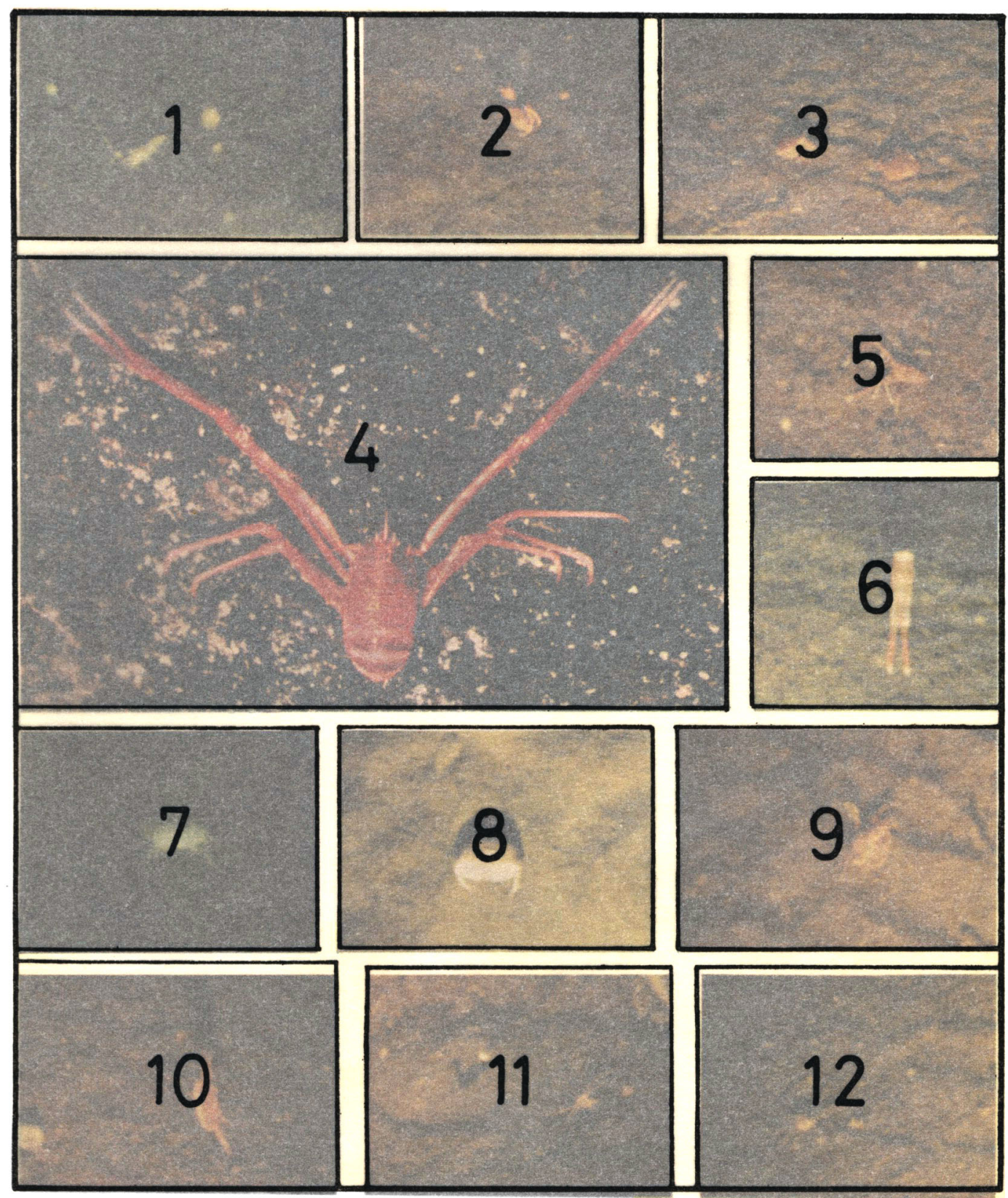



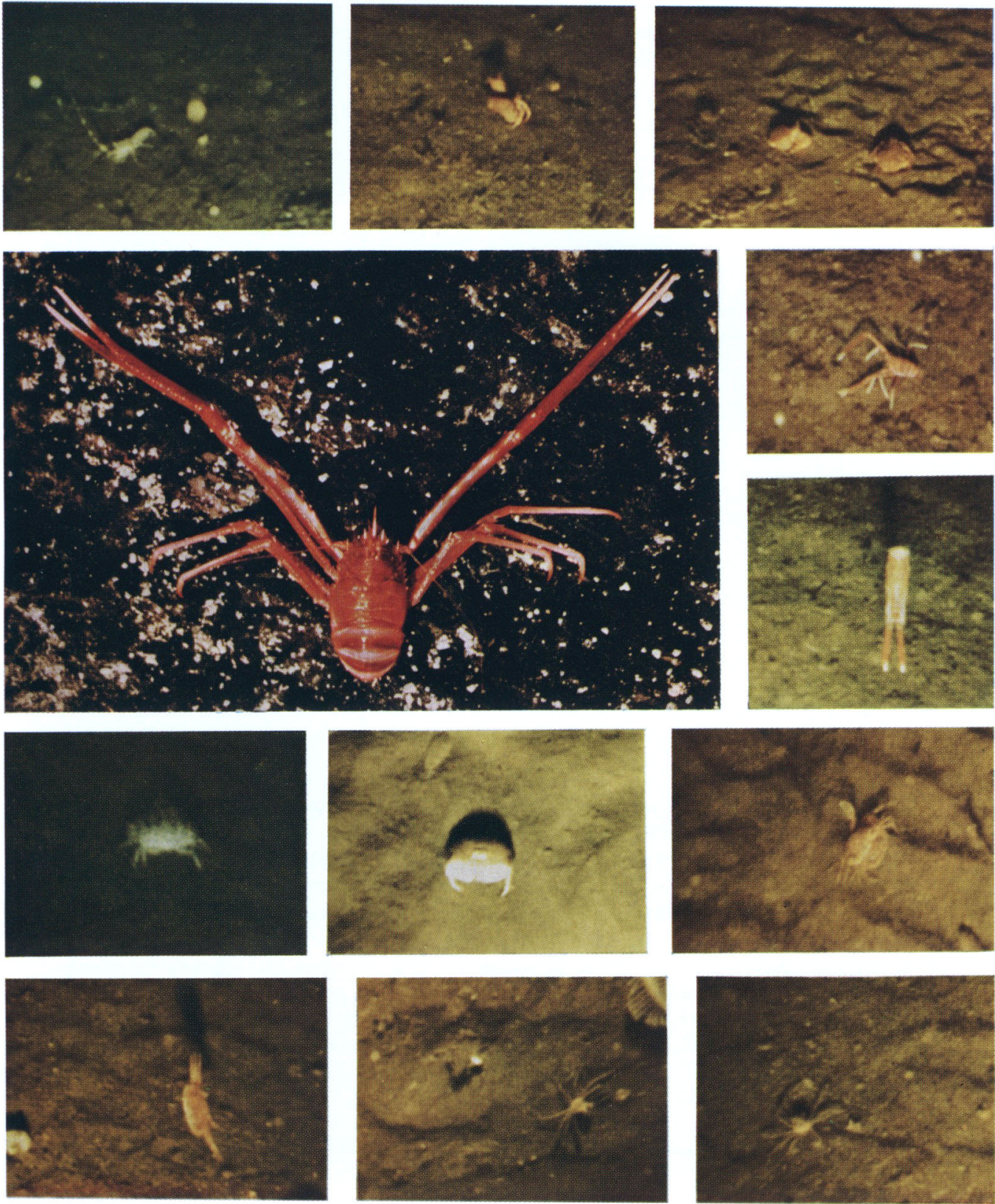